\title{
The infection process of the reef coral Stylophora pistillata by the parasitic copepod, Xarifia obesa
}

Received: 16 February 2009/ Accepted: 11 March 2009/Published online: 2 April 2009

(C) Springer-Verlag 2009
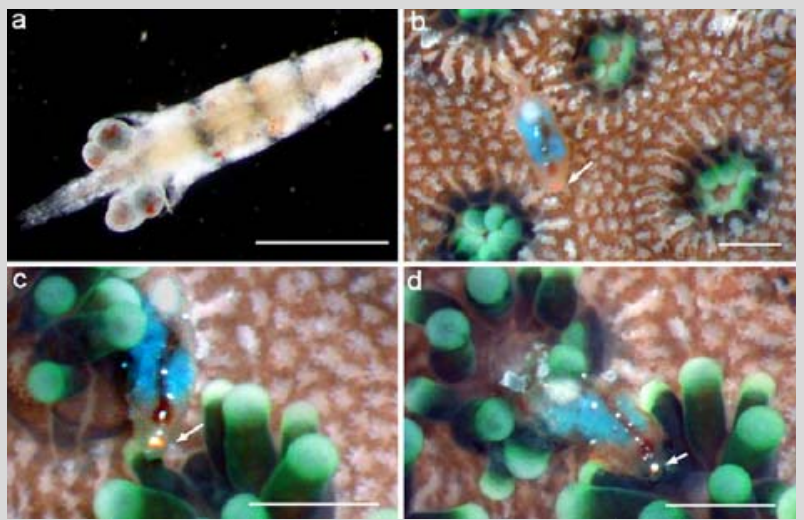

Fig. 1 a An individual of Xarifia obesa; b X. obesa seeking polyps after being re-introduced to a coral colony; c Coral polyps start to extend their tentacles when in contact with $X$. obesa; d After the relaxation of coral polyps, X. obesa quickly enter the gastrovascular cavity of a polyp. Scale bars $=0.5 \mathrm{~mm}$. Arrows indicate the head of $X$. obesa
Copepods are common parasites of scleractinians and octocorals (Humes 1985a). Among them, the family Xarifiidae which comprises 86 species in 4 genera is a group of coral-specific endoparasites widely distributed in Indo-Pacific coral reefs (Humes 1985b). How the Xarifiids establish intimate associations with their host corals without being killed by nematocysts is still unknown.

When studying the parasitic copepods on corals from Taiwan, we observed $(n=4)$ the behavior of Xarifia obesa Humes and Ho, 1968 (Fig. 1a) by reintroducing it to a pocilloporid coral, Stylophora pistillata (Esper, 1797). When $X$. obesa was reintroduced to the surface of the coral colony, it started to search for polyps (Fig. 1b). When $X$. obesa approached a coral polyp, tentacles of the polyp began expanding gradually (Fig. 1b, c). The tentacle-expanding behavior is similar to the initial feeding behavior of coral polyps when detecting a prey (Lin et al. 2002). However, unlike the retraction of tentacles,

which occurs when prey is captured, no tentacle retraction was observed when in contact with the xarifiid. The xarifiid then entered the polyp quickly (Fig. 1d). These phenomena suggest that the xarifiids may release chemicals to induce the relaxation of coral polyps and are likely immune to the nematocysts of corals. These characteristics enable the xarifiids and possibly other parasitic copepods to establish close associations with their host corals. The mechanism and evolutionary significance of coral-parasite associations invite further studies.

\section{References}

Humes AG (1985a) Cnidarians and copepods: a success story. Trans Am Microsc Soc 104:313-320

Humes AG (1985b) A review of the Xarifiidae (Copepoda, Poecilostomatoida), parasites of scleractinian corals in the Indo-Pacific. Bull Mar Sci 36:467-632

Lin MC, Liao CM, Dai CF (2002) Modeling the effects of satiation on the feeding rate of a colonial suspension feeder, Acanthogorgia vegae, in a circulating system under lab conditions. Zool Stud 41:355-365

Y.-R.Cheng · C.-F.Dai $(\bowtie)$

Institute of Oceanography, National Taiwan University, No. 1 Roosevelt Road, Section 4, Taipei 106, Taiwan e-mail: corallab@ntu.edu.tw 